\title{
FoxM1 mediated resistance to gefitinib in non-small- cell lung cancer cells
}

\author{
Nuo $X U^{1, \#}$, Xin ZHANG ${ }^{1, \#}$, Xun WANG ${ }^{1}$, Hai-yan $\mathrm{GE}^{1}$, Xiao-ying WANG ${ }^{1}$, David GARFIELD ${ }^{2}$, Ping YANG ${ }^{3}$, Yuan-lin SONG ${ }^{1}$, \\ Chun-xue BAl ${ }^{1, *}$ \\ ${ }^{1}$ Department of Pulmonary Medicine, Zhongshan Hospital, Fudan University, Shanghai 200032, China; ${ }^{2}$ ProMed Cancer Centers - \\ Shanghai, Shanghai 200020, China; ${ }^{3}$ Department of Health Sciences Research, Mayo Clinic, Rochester, MN 55905, USA
}

\begin{abstract}
Aim: Gefitinib is effective in only approximately $20 \%$ of patients with non-small-cell lung cancer (NSCLC), and the underlying mechanism remains unclear. FoxM1 is upregulated in NSCLC and associated with a poor prognosis in NSCLC patients. In this study, we examined the possible role of FoxM1 in gefitinib resistance and the related mechanisms.

Methods: Gefitinib resistant human lung adenocarcinoma cell line SPC-A-1 and gefitinib-sensitive human lung mucoepidermoid carcinoma cell line $\mathrm{NCl}-\mathrm{H} 292$ were used. mRNA and protein expression of FoxM1 and other factors were tested with quantitative RT PCR and Western blot analysis. RNA interference was performed to suppress FoxM1 expression in SPC-A-1 cells, and lentiviral infection was used to overexpress FoxM1 in $\mathrm{H} 292$ cells. MTT assay and flow cytometry were used to examine the proliferation and apoptosis of the cells.

Results: Treatment of SPC-A-1 cells with gefitinib ( 1 and $10 \mu \mathrm{mol} / \mathrm{L})$ upregulated the expression of FoxM1 in time- and concentrationdependent manners, while gefitinib $(1 \mu \mathrm{mol} / \mathrm{L})$ downregulated in $\mathrm{H} 292$ cells. In SPC-A-1 cells treated with gefitinib (1 $\mu \mathrm{mol} / \mathrm{L})$, the expression of several downstream targets of FoxM1, including survivin, cyclin B1, SKP2, PLK1, Aurora B kinase and CDC25B, were significantly upregulated. Overexpression of FoxM1 increased the resistance in $\mathrm{H} 292$ cells, while attenuated FoxM1 expression restored the sensitivity to gefitinib in SPC-A-1 cells by inhibiting proliferation and inducing apoptosis.

Conclusion: The results suggest that FoxM1 plays an important role in the resistance of NSCLC cells to gefitinib in vitro. FoxM1 could be used as a therapeutic target to overcome the resistance to gefitinib.
\end{abstract}

Keywords: FoxM1; non-small-cell lung cancer; gefitinib; drug resistance; RNA interference; human lung adenocarcinoma cell; human lung mucoepidermoid carcinoma cell

Acta Pharmacologica Sinica (2012) 33: 675-681; doi: 10.1038/aps.2011.188; published online 26 Mar 2012

\section{Introduction}

Forkhead box M1 (FoxM1), a member of the Fox family of transcriptional factors, has been shown to be essential for cell cycle progression and plays an important role in cell-cycle regulation by controlling the transition from $G_{1}$ to $S$ phase, as well as the entry into and completion of mitosis ${ }^{[1-4]}$. FoxM1 mainly functions through the regulation of several cell cycle effectors, including p27/Kip1, cyclin B1, CDC25B, survivin, Cks1, pololike kinase-1 (PLK1) and Aurora B kinase ${ }^{[5-8]}$. Downregulation of FoxM1 expression could thus cause cell cycle arrest, chromosome misaggregation and spindle defects. Moreover, FoxM1 was also found to be overexpressed in a wide range of solid tumors, including lung, liver and breast cancers ${ }^{[7,9-11]}$.

\footnotetext{
\# These authors contributed equally to this paper.

* To whom correspondence should be addressed.

E-mail bai.chunxue@zs-hospital.sh.cn

Received 2011-07-09 Accepted 2011-12-06
}

In addition, the function of FoxM1 was reported to be mediated by phosphoinositide-3-kinase (PI3K)/AKT signaling, one of the epidermal growth factor receptor (EGFR) downstream signaling pathways ${ }^{[12]}$. Gefitinib, an EGFR inhibitor, can block downstream signaling pathways, such as PI3K/AKT and Ras/Raf/MAPK, by competitively binding to the EGFR receptor tyrosine kinase domain ${ }^{[13-16]}$. However, the dysregulation of PI3K/AKT signaling has been reported to contribute to the resistance of non-small-cell lung cancer (NSCLC) to epidermal growth factor receptor tyrosine kinase inhibitors (EGFR-TKIs) $^{[17,18]}$. This suggests that FoxM1 plays a role in the resistance of NSCLC to gefitinib.

In this study, we investigated whether FoxM1 overexpression in the EGFR-positive SPC-A-1 NSCLC cell line could confer resistance to gefitinib, and whether downregulation of FoxM1 expression could sensitize such cells to therapy. We found that FoxM1 not only mediates the inherent resistance of NSCLC cells to the EGFR-TKI, gefitinib, but may also be used 
as a biomarker to predict the response of NSCLC patients to this agent.

\section{Materials and methods}

\section{Cell lines, cell culture and chemotherapeutic reagents}

The human lung adenocarcinoma cell line SPC-A-1 was obtained from the Cellular Institute of the Chinese Academy of Science (Shanghai, China). The cell line was established in 1980 from a surgical specimen of a Chinese male patient with advanced lung adenocarcinoma by the Shanghai Chest Hospital and Cellular Institute of Chinese Academy of Science $^{[19]}$. The human lung mucoepidermoid carcinoma cell line NCI-H292 was purchased from the Cellular Institute of Chinese Academy of Science. These cells were cultured at $37^{\circ} \mathrm{C}$ under a $5 \% \mathrm{CO}_{2}$ atmosphere in Dulbecco's modified Eagle's medium (DMEM), and supplemented with 10\% fetal bovine serum (FBS, Hyclone, UT, USA), $100 \mathrm{U} / \mathrm{mL}$ penicillin, and 100 $\mu \mathrm{g} / \mathrm{mL}$ streptomycin. Cells were regularly certified as free of mycoplasma contamination. Gefitinib (AstraZeneca) was dissolved in DMSO at various concentrations and quantities, per the experimental design. The cells were counted 3 times using a hemocytometer, seeded to an appropriate confluence and incubated for certain durations depending on the intended application.

\section{MTT assays}

Cell growth was evaluated by 3-(4,5-dimethylthiazol-2-yl)-2, 5-diphenyltetrazolium bromide (MTT) assays according to previous reports ${ }^{[20]}$. After shaking for $10 \mathrm{~min}$ at room temperature, the optical density (OD) of each well was examined by a plate reader at a $490 \mathrm{~nm}$ test wavelength.

\section{FCM analysis}

Cells were harvested $72 \mathrm{~h}$ after administration of gefitinib, trypsinized and washed twice with complete media. Aliquots of cells $\left(1 \times 10^{6}\right)$ were resuspended and stained with fluorescein isothiocyanate (FITC)-labeled annexin- $\mathrm{V}$ according to the manufacturer's instructions. Propidium iodide (PI) was subsequently added to the samples, followed by a $30 \mathrm{~min}-$ incubation with annexin-V stain in the dark. Flow cytometry (BD, FACSCalibur, USA) was performed immediately after staining.

\section{SiRNA analyses}

Small interfering RNA (siRNA) for FoxM1 (5'-GCCGGAACAUGACCAUCAATT-3') and negative control siRNA (5'-UUCUCCGAACGUGUCACGUTT-3') were purchased from Genepharma (Shanghai, China). According to the manufacturer's protocol, cells were transfected using the Lipofectamine 2000 reagent (Invitrogen, USA). The cells were harvested after $48 \mathrm{~h}$ of transfection. The depletion of FoxM1 was determined by real-time PCR.

\section{Transduction of tumor cells}

The plasmid (EX-Z5438-LV135) and the Lenti-Pac ${ }^{\mathrm{TM}}$ HIV Expression Packaging Kit were purchased from GeneCopoeia
Inc (Guangzhou, China). Transductions of H292 cells were performed according to instructions supplied by the manufacturers. Stable transfectants were further confirmed by both RT-PCR and immunoblotting based on their FoxM1 expression.

\section{Quantitative real-time PCR}

Total RNA was extracted using TRIzol reagent (Invitrogen, USA), and cDNA was synthesized using reverse transcriptase (TaKaRa, Japan). GAPDH was used as the internal control to quantitate initial cellular transcripts. Primer sequences included the following:

FoxM1 sense 5'-AAGAACTCCATCCGCCACAAC-3', FoxM1 anti-sense 5'-GCTTAAACACCTGGTCCAATGTC-3'.

GAPDH sense 5'-ATACTCCTGCTTGCTGATCC-3', GADPH anti-sense 5'-CCTGTACGCCAACACAGTGC-3'.

Survivin sense 5'-AACCAGACCCTCATGGCTAC-3', Survivin anti-sense 5'-TTCCCAGACTCCACTCCAAC-3'.

PLK1 sense 5'-CCCCTCACAGTCCTCAATA-3', PLK1 antisense 5'-TGTCCGAATAGTCCACCC-3'.

Cyclin B1 sense 5'-GTTGGTTTCTGCTGGGTG-3', Cyclin B1 anti-sense 5'-ATGTTGATCTTCGCCTTA-3'.

Aurora B kinase sense 5'-CTCTGGGCAAAGGCAAGT-3', Aurora B kinase anti-sense 5'-ACGCAGGATGTTGGGATG-3'. CDC25B sense 5' -TCAAATATCAGTTACCCACTCG-3', CDC25B anti-sense 5'-TCCATCCGCAACAAGACA-3'.

Skp2 sense 5'-GAAAGAGGAGCCCGACAG-3', Skp2 antisense 5'-CTCAGGGAGGCACAGACA-3'.

The amplification data, measured by fluorescence, were collected in real-time and analyzed by the Rotor-Gene 3000 software.

\section{Western blot}

A Western blot was performed with whole cell extracts by the protocols described previously ${ }^{[21]}$. The antibodies used were anti- $\beta$-actin antibody (1:5000, Abcam), rabbit polyclonal antiFoxM1 antibody (1:2000, Santa Cruz Biotechnology), rabbit monoclonal anti-survivin antibody $(1: 1000, \mathrm{CST})$ or rabbit polyclonal anti-cyclin B1 antibody (1:1000, CST), rabbit monoclonal anti-Skp2 antibody (1:1000, CST), rabbit monoclonal anti-Aurora B kinase antibody (1:1000, CST), rabbit monoclonal anti-PLK1 antibody (1:1000, CST), and rabbit monoclonal anti-CDC25B antibody (1:1000, CST). $\beta$-Actin was used as the loading control. Protein was visualized using enhanced chemiluminescence (ECL). Quantification was performed using the Image J software.

\section{Statistical analysis}

Data are presented as the mean \pm standard deviation (SD) and were evaluated with the paired, two-tailed Student's t-test. $P<0.05$ was accepted as statistically significant.

\section{Results}

Expression levels of FoxM1 increased after gefitinib treatment in the resistant cell line but decreased in the sensitive cell line

To investigate whether the expression of FoxM1 was changed 
by treatment with gefitinib, we applied different gefitinib concentrations to the resistant cell line, SPC-A-1 $(1 \mu \mathrm{mol} / \mathrm{L}$ and 10 $\mu \mathrm{mol} / \mathrm{L})$, and to the sensitive cell line, H292 ( $1 \mu \mathrm{mol} / \mathrm{L})$, for 0 , 24, 48, and 72 h, respectively. Expression levels of FoxM1 were measured by qRT-PCR and Western blot analysis. As shown in Figure 1A and 1B, mRNA expression levels of FoxM1 in gefitinib-treated SPC-A-1 cells increased at 24, 48, and $72 \mathrm{~h}$, compared with the untreated control group. Moreover, the protein levels of FoxM1 in the treated group were also upregulated, with a 2 to 10 fold increase compared with the control group (Figure 1C). In contrast, the mRNA and protein levels of FoxM1 were significantly reduced in the H292 cells (Figure
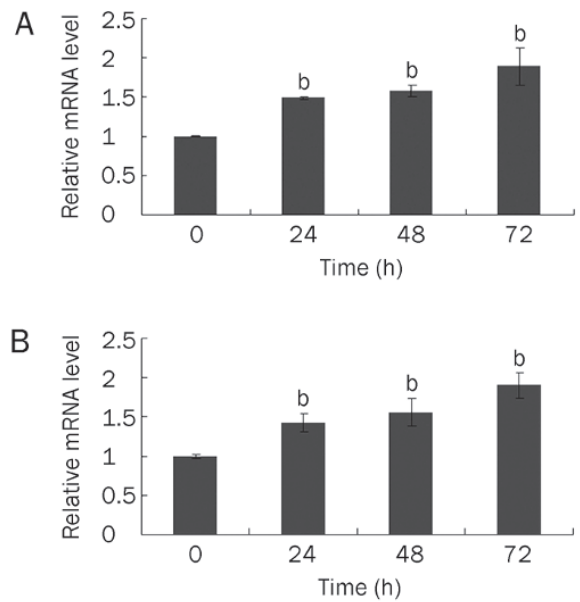

C
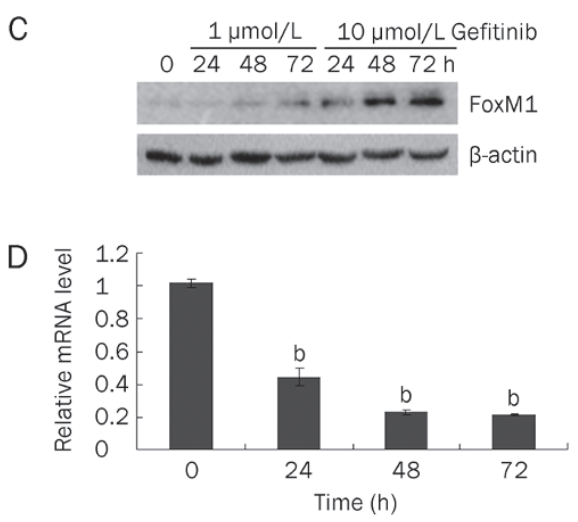

E

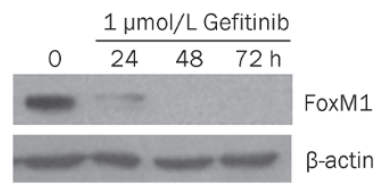

Figure 1. Expression level of FoxM1 in the resistant and sensitive lung cancer cells with gefitinib treatment. (A and B) mRNA expression of FoxM1 in gefitinib-resistant SPC-A-1 lung cancer cell line upon the treatment of $1 \mu \mathrm{mol} / \mathrm{L}(\mathrm{A})$ and $10 \mu \mathrm{mol} / \mathrm{L}(\mathrm{B})$ concentration of gefitinib for 24, 48, and 72 h. (C) Protein expression level of FoxM1 in SPC-A-1 lung cancer cell line upon treatment of $1 \mu \mathrm{mol} / \mathrm{L}$ and $10 \mu \mathrm{mol} / \mathrm{L}$ concentration of gefitinib for 24,48 , and 72 h. $\beta$-actin was used as a loading control. mRNA (D) and protein (E) levels of FoxM1 in gefitinib-sensitive $\mathrm{NCl}-\mathrm{H} 292$ cells upon treatment of $1 \mu \mathrm{mol} / \mathrm{L}$ concentration of gefitinib for 24,48 , and $72 \mathrm{~h}$. Mean \pm SD. ${ }^{\mathrm{b}} \mathrm{P}<0.05$ vs control.
1D and 1E). Together, these results indicated that FoxM1 showed a different expression pattern between resistant and sensitive NSCLC cell lines treated with gefitinib, implying that FoxM1 has an important role in the resistance of such cells to gefitinib.

\section{Increased expression of FoxM1 contributed to the resistance of} NSCLC cells to gefitinib

To determine whether an increase of FoxM1 expression plays a role in the resistance of NSCLC cells to gefitinib, FoxM1 expression was first knocked down by RNA interference in SPC-A-1 cells, which was confirmed by qRT-PCR (Figure 2A). Cells undergoing transfection of siRNAs were also incubated with gefitinib for $72 \mathrm{~h}$, respectively. As shown in Figure 2B, survival rates of SPC-A-1 cells significantly decreased $(P<0.05)$ in the group that was transfected with siRNAs against FoxM1 (siRNA-FoxM1) compared with the siRNA-targeting negative control (siRNA-NC), with all cells being exposed to different concentrations of gefitinib treatment $(0,0.1,1,5,10$, and $20 \mu \mathrm{mol} / \mathrm{L})$. In addition, the apoptosis rate of SPC-A-1 cells significantly increased from $7.55 \%$ to $14.11 \%$ and from $8.88 \%$ to $18.69 \%$ in the siRNA-FoxM1 groups compared with the siRNA-NC groups, with $1 \mu \mathrm{mol} / \mathrm{L}$ and $10 \mu \mathrm{mol} / \mathrm{L}$ gefitinib concentrations, respectively (Figure 2C). These data strongly suggest that FoxM1 plays an important role in the resistance of SPC-A-1 cells to gefitinib, implying that targeting FoxM1 could sensitize SPC-A-1 cells to the drug.

To further demonstrate the role of FoxM1 in the resistance to gefitinib, we employed lentiviral transfection in order to establish FoxM1 overexpressing cells (H292-FoxM1), which was confirmed at the mRNA (Figure 3A) and protein levels (Figure 3B). Consistently, when treated with 0, 0.25, 0.5, 1, 2, and $4 \mu \mathrm{mol} / \mathrm{L}$ concentrations of gefitinib for $72 \mathrm{~h}$, the survival rate of H292-FoxM1 increased (Figure 3C), while the apoptosis rate was abrogated with the treatment of $1 \mu \mathrm{mol} / \mathrm{L}$ and 2 $\mu \mathrm{mol} / \mathrm{L}$ concentrations of gefitinib (Figure 3D). These data suggest that the introduction of FoxM1 can protect lung cancer cells against gefitinib.

FoxM1 mediated the resistance of lung cancer cells to gefitinib by the upregulation of downstream targeted genes

To further explore the mechanisms of how FoxM1 may mediate the resistance of SPC-A-1 cells to gefitinib, the expression levels of several cell cycle-related genes were examined, including Aurora B kinase, Skp2, PLK1, CDC25B, survivin, and cyclin B1, all known targets of FoxM1. These targets participate in multiple cellular functions, including cytoprotection, cell death, and cell cycle regulation. As shown in Figure 4A, mRNA expression levels of these downstream targets were significantly upregulated in gefitinib-treated SPC-A-1 cells $(1 \mu \mathrm{mol} / \mathrm{L}$ and $10 \mu \mathrm{mol} / \mathrm{L})$ for $48 \mathrm{~h}$. When treated with a $1 \mu \mathrm{mol} / \mathrm{L}$ concentration of gefitinib, the mRNA expression levels of survivin, cyclin B1, SKP2, PLK1, Aurora B kinase and $\mathrm{CDC} 25 \mathrm{~B}$ increased. Additionally, when treated with 10 $\mu \mathrm{mol} / \mathrm{L}$ gefitinib, the expression levels of the downstream targets survivin, cyclin B1, SKP2, PLK1, Aurora B kinase and 

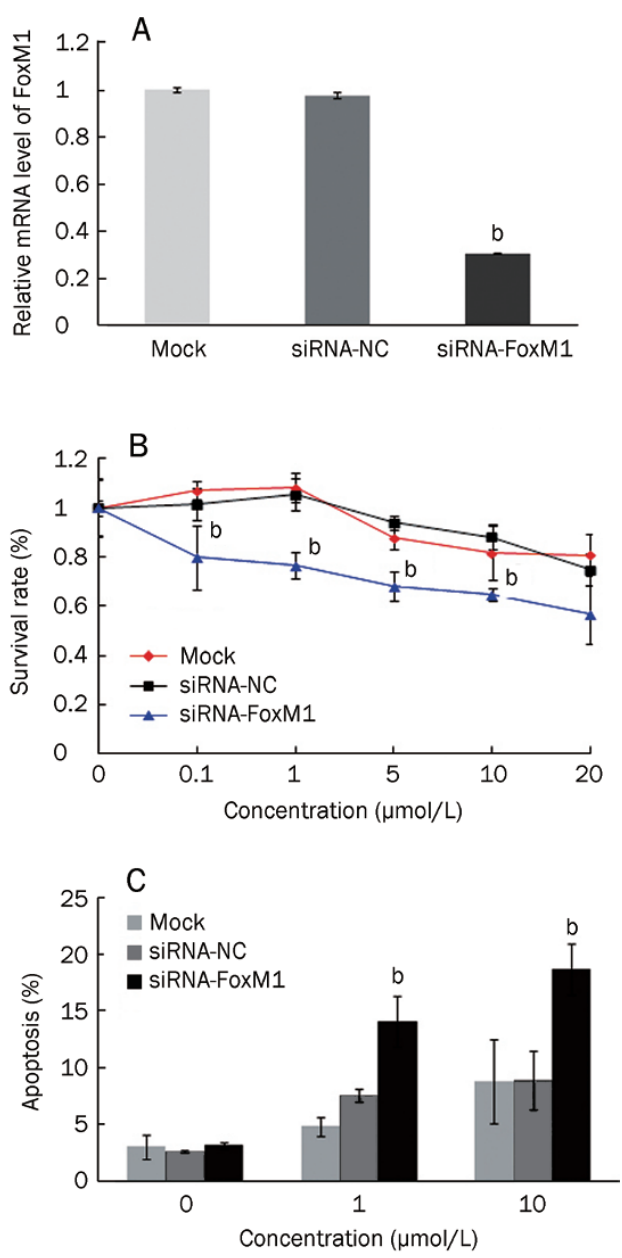

Figure 2. Survival rate and apoptosis rate of SPC-A-1 cells in SiRNAFoxM1, siRNA-NC, and mock groups. (A) qRT-PCR assays of FoxM1 expression level in SPC-A-1 cells transfected with indicated siRNAs. (B) Survival rate of SPC-A-1 cells in siRNA-FoxM1 (blue line), siRNA-NC (black line), and mock (red line) groups with the treatment of $0,0.1,1,5,10$, and $20 \mu \mathrm{mol} / \mathrm{L}$ concentrations of gefitinib for $72 \mathrm{~h}$. Apoptosis rate of SPC-A-1 cells in the siRNA-FoxM1, siRNA-NC, and mock groups with the treatment of $1 \mu \mathrm{mol} / \mathrm{L}$ and $10 \mu \mathrm{mol} / \mathrm{L}$ concentration of gefitinib for $72 \mathrm{~h}$. Mean $\pm S D$. ${ }^{\mathrm{b}} \mathrm{P}<0.05$ vs the mock and siRNA-NC groups.

CDC 25B increased in the resistant cell line compared with the control (Figure 4A).

Among these factors, there was a significant increase in survivin and cyclin B1 expression as compared to the other factors. Thus, they were chosen for further examination of their protein levels in the resistant cell line. As shown in Figure 4B, the expression levels of both genes were significantly upregulated in cells treated with gefitinib $(1 \mu \mathrm{mol} / \mathrm{L}$ and $10 \mu \mathrm{mol} / \mathrm{L})$ for $0,24,48$, and $72 \mathrm{~h}$, respectively.

Furthermore, we examined the expression levels of these factors in SPC-A-1 siRNA-FoxM1 and H292-FoxM1 cell lines. A decrease in Aurora B kinase, cyclin B1, survivin and Skp2 (Figure 5A, 5C) expression was observed in SPC-A-1 cells transfected with siRNA against FoxM1. An increase of Aurora

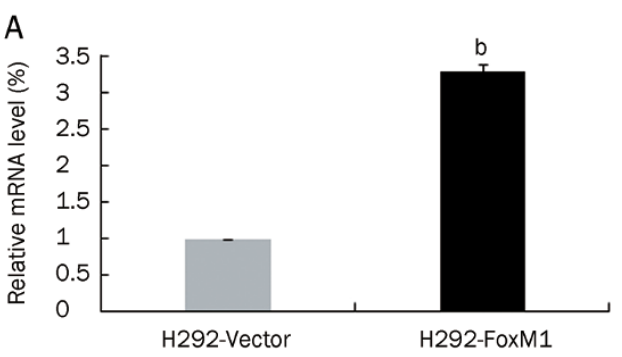

B
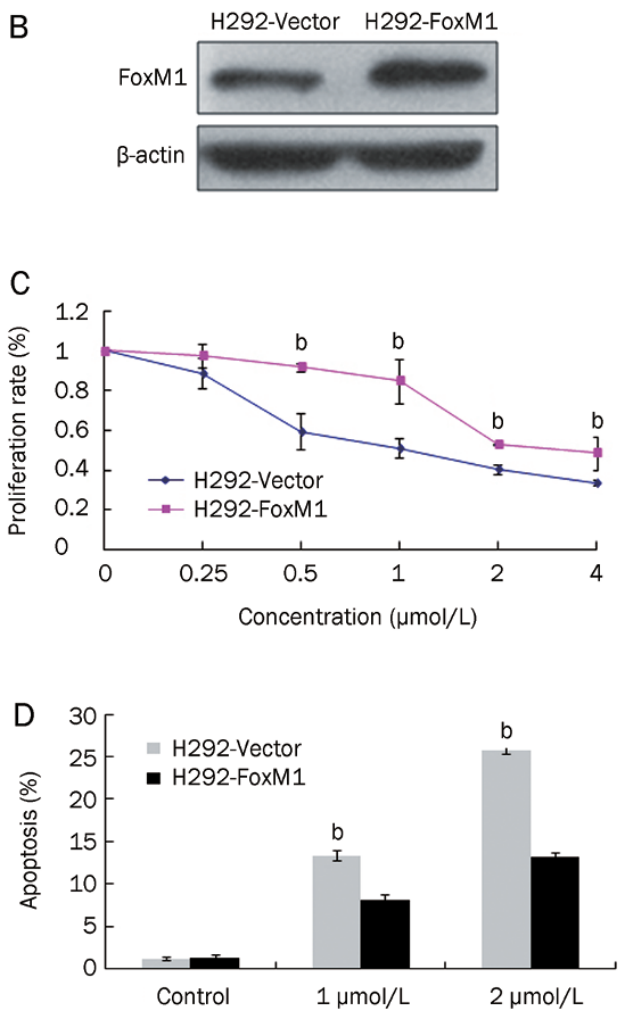

Figure 3. Survival rate and apoptosis rate of H292 cells overexpressiong FoxM1. (A) qRT-PCR assays of FoxM1 expression level in H292 cells with lenti-virus infection. (B) Western blot analysis of FoxM1 expression level in $\mathrm{H} 292$ cells with lenti-virus infection. $\beta$-actin was used as a loading control. (C) Survival rate of $\mathrm{H} 292$ cells in H292-FoxM1 (red line) and vector (blue line) groups with the treatment of $0,0.25,0.5,1,2$, and 4 $\mu \mathrm{mol} / \mathrm{L}$ concentrations of gefitinib for $72 \mathrm{~h}$. (D) Apoptosis rate of H292 cells in the H292-FoxM1 and vector groups with the treatment of $1 \mu \mathrm{mol} / \mathrm{L}$ and $2 \mu \mathrm{mol} / \mathrm{L}$ concentration of gefitinib for $72 \mathrm{~h}$. Mean \pm SD. ${ }^{\mathrm{b}} P<0.05 \mathrm{vs}$ the vector group.

B kinase, cyclin B1, survivin and Skp2 (Figure 5B, 5D) was observed in H292-FoxM1 cells, which revealed that an overexpression of FoxM1 conferred the resistance of NSCLC cells to gefitinib. Taken together, these data suggest that FoxM1 mediated the resistance of lung cancer cells to gefitinib, probably by upregulating the expression of several downstream targets of FoxM1, including Aurora B kinase, Skp2, PLK1, CDC25B, survivin and cyclin B1, which are all important factors in the regulation of cell cycle progression and proliferation. 

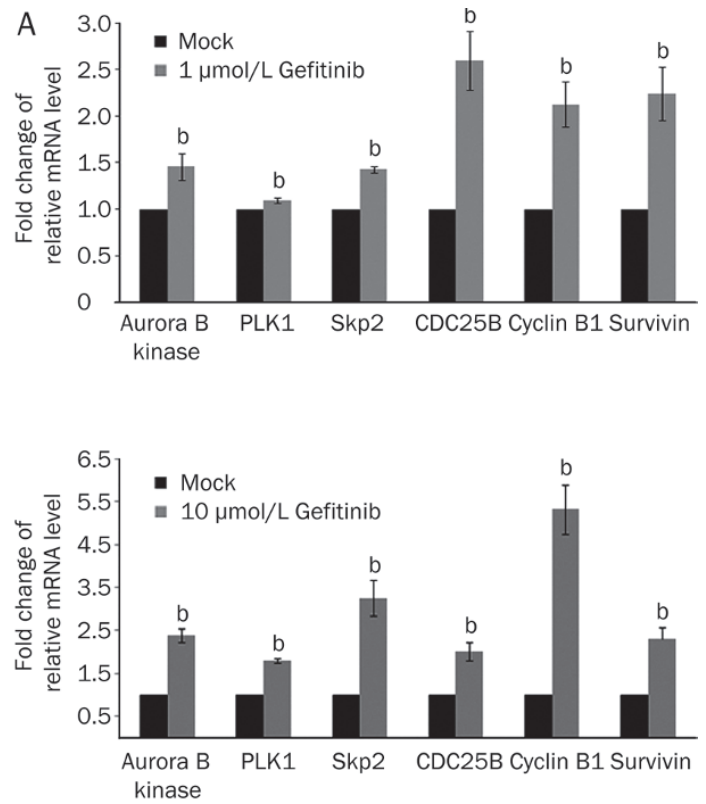

B

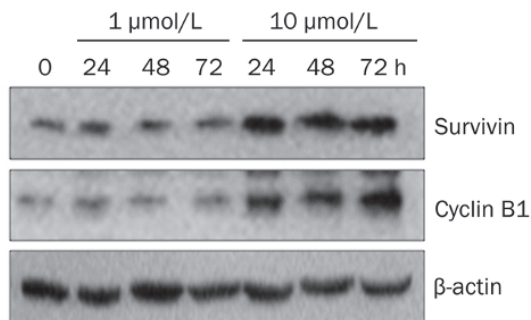

Figure 4. Expression levels of downstream targets of FoxM1 in the SPC-A-1 cells with gefitinib treatment. (A) mRNA expression levels of downstream targets of FoxM1 with treatment of $1 \mu \mathrm{mol} / \mathrm{L}$ and 10 $\mu \mathrm{mol} / \mathrm{L}$ concentration of gefitinib for $48 \mathrm{~h}$. (B) Protein level of cyclinB1 and survivin in the SPC-A-1 cells with the treatment of $1 \mu \mathrm{mol} / \mathrm{L}$ and 10 $\mu \mathrm{mol} / \mathrm{L}$ concentration of gefitinib for 24,48 , and $72 \mathrm{~h}$. $\beta$-actin was used as a loading control. Mean \pm SD. ${ }^{\mathrm{b}} P<0.05$ vs the mock group.

\section{Discussion}

According to the World Health Organization, lung cancer is responsible for more than 1.3 million deaths every year. Although there have been advances in cancer treatment, drug resistance is the most common cause of therapy failure in lung cancer patients ${ }^{[22]}$. FoxM1, a member of the Forkhead box family of transcription factors, is known to play an important role in cell cycle progression ${ }^{[23,24]}$ and is overexpressed in a panel of solid tumors, including liver, lung, cervical, colorectal and breast cancers ${ }^{[7,9-11]}$. FoxM1 also participates in the drug resistance of various cancer cells by protecting cancer cell proliferation and abrogating apoptosis ${ }^{[25,26]}$. For example, enhanced expression of FoxM1 was reported to inhibit cell death induced by gefitinib in some breast cancer cell lines ${ }^{[15]}$. However, gefitinib can also inhibit the expression of FoxM1 in sensitive breast cancer cells ${ }^{[27]}$. These findings suggest that FoxM1 has an important role in gefitinib-induced proliferative

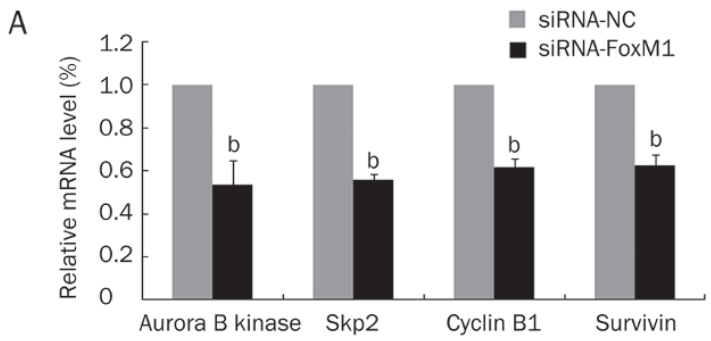

B
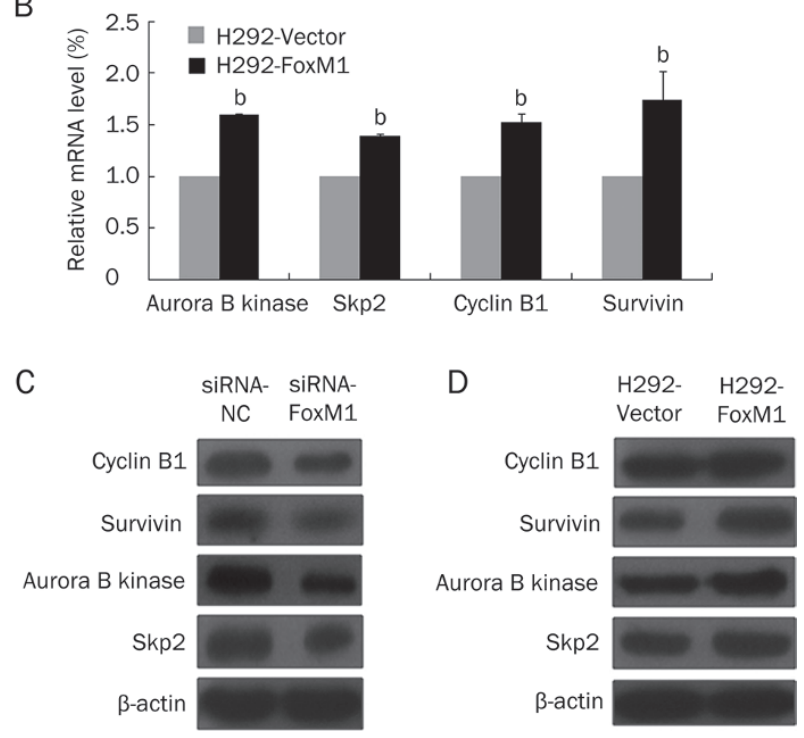

Figure 5. Expression levels of downstream targets when FoxM1 was knockdown in SPC-A-1 and overexpressed in H292 cells. (A) mRNA expression levels of downstream targets of FoxM1 in SPC-A-1 siRNAFoxM1 (black bar) and siRNA-NC (grey bar) groups. (B) mRNA expression levels of downstream targets of FoxM1 in H292-FoxM1 (black bar) and vector (grey bar) groups. Quantification values normalized to GAPDH are shown as mean \pm SD. (C) Protein levels of downstream targets of FoxM1 in siRNA-FoxM1 and siRNA-NC groups. $\beta$-actin was used as a loading control. (D) Protein levels of downstream targets of FoxM1 in H292-FoxM1 and vector groups. $\beta$-actin was used as a loading control. Mean \pm SD. ${ }^{b} P<0.05$ vs the siRNA-NC or vector group.

arrest. Thus, its expression might be used to determine the sensitivity of breast cancer cells to gefitinib. It is important to note that attenuating the activity of FoxM1 in traztuzumabresistant breast cancer cells has also been shown to increase their sensitivity to traztuzumab, a tyrosine kinase receptor antibody inhibitor that targets the HER2 oncogene product. Traztuzumab, in fact, shares similar signaling pathway inhibition with gefitinib, including PI3K/ $\mathrm{Akt}^{[26]}$. Moreover, the knockdown of FoxM1 expression can induce apoptosis in breast cancer cells that are otherwise resistant to cisplatin ${ }^{[25]}$. However, the role of FoxM1 in the EGFR-TKI resistance of NSCLC is largely unknown.

In this study, we show that treatment with gefitinib not only decreases FoxM1 expression in sensitive H292 lung cancer cells, which is consistent with previous studies demonstrat- 
ing that gefitinib repressed expression of FoxM1 in sensitive breast cancer cell lines ${ }^{[27]}$, but also that gefitinib paradoxically increases FoxM1 expression in resistant SPC-A-1 lung cancer cells. Additionally, to determine if FoxM1 has the ability to confer resistance to NSCLC cells exposed to gefitinib, we knocked down FoxM1 expression in the resistant SPC-A-1 cells, and overexpressed it in the sensitive H292 cells. The results showed that when FoxM1 was suppressed, the proliferation of SPC-A-1 cells was inhibited and apoptosis was increased, while the overexpression of FoxM1 enhanced the resistance of $\mathrm{H} 292$ cells to gefitinib. Taken together, these findings strongly suggest that FoxM1 plays an important role in gefitinib-resistant cells through promoting cell proliferation and inhibiting apoptosis. Importantly, the inhibition of FoxM1 expression partially restores sensitivity to gefitinib in the otherwise resistant cells.

To further determine the molecular mechanism by which FoxM1 contributes to gefitinib resistance in the resistant cells, the expression levels of several FoxM1-targeted genes implicated in drug resistance, including Aurora B kinase, Skp2, PLK1, CDC25B, survivin and cyclin B1, were analyzed ${ }^{[28,29]}$. Through gene amplification of Aurora B kinase, Skp2, PLK1, CDC25B, survivin and cyclin B1, FoxM1 promotes $\mathrm{G}_{1}-\mathrm{S}$ and $\mathrm{G}_{2}-\mathrm{M}$ transition and mitosis. We also found that the mRNA expression levels of these genes significantly increased with gefitinib exposure, possibly contributing to gefitinib resistance. In addition, among these factors, survivin and cyclin B1 increased more significantly with exposure to gefitinib than the other factors. Survivin, a member of the inhibitor of apoptosis (IAP) family, has been reported to function in chemotherapy and radiation therapy resistance ${ }^{[30]}$. Thus, survivin has been a target for therapy in several cancers, including rectal, ovarian and esophageal cancers ${ }^{[30-32]}$. These findings suggest that an increase of survivin in cancer cells would decrease chemotherapy sensitivity. Cyclin B1, a $G_{2}$ /mitotic-specific cyclin, is essential for the transition from $G_{2}$ to mitosis, and it has been implicated in the drug-resistance of several cancers ${ }^{[3,34]}$. For example, targeting cyclin B1 inhibits proliferation in several breast and cervical cancer cell lines, and sensitized breast cancer cells to paclitaxe ${ }^{[29]}$. In addition, in head and neck squamous cell carcinomas, the overexpression of cyclin B1 correlates with radiotherapy resistance ${ }^{[34]}$, and nuclear cyclin B1-positive breast carcinomas are resistant to hormonal, radioand chemotherapy adjuvant treatment ${ }^{[33]}$.

We have demonstrated that FoxM1 can upregulate the expression levels of survivin, cyclin B1 and other downstream cell cycle regulators in SPC-A-1 cells treated with gefitinib. The expression of the downstream targets could be decreased with low FoxM1 expression and thus lead to the reduced proliferation and enhanced apoptosis of tumor cells. Moreover, these downstream targets could be upregulated with high FoxM1 expression and may increase proliferation and decrease apoptosis in tumor cells. This implies that these molecules participate in the FoxM1-mediated resistance of NSCLC cells to gefitinib, thereby reducing drug sensitivity. Thus, the deregulation of FoxM1 and its downstream targets may play a pivotal clinical role in NSCLC resistance to gefitinib. Our results could help explain the results of the phase III clinical study ISEL (Iressa Survival Evaluation in Lung Cancer). In this study, it was demonstrated that gefitinib, employed as a second-line treatment alone, failed to show clinical benefit compared with the placebo group ${ }^{[35]}$. This could be due to gefitinib's induction of survivin and cyclin B1 expression in resistant cases, thus suppressing its efficacy.

In summary, we have found that FoxM1 can mediate and even increase the resistance of NSCLC cells to gefitinib, perhaps by increasing the expression of its downstream targets, survivin and cyclin B1 in particular, indicating that targeting FoxM1 for inhibition could sensitize otherwise resistant NSCLC cells to gefitinib. To the best of our knowledge, this report demonstrated that FoxM1 overexpression in the clinical setting might provide protection for NSCLC tumors from gefitinib, suggesting that FoxM1 targeting might be an attractive strategy for use in combination with conventionally used cytotoxic agents and/or target therapy.

\section{Acknowledgements}

This work was supported by the Shanghai Leading Academic Discipline Project( № B115) and China National "985" Project (phase III).

\section{Author contribution}

Nuo XU and Xin ZHANG performed the research and wrote the paper; Xun WANG, Hai-yan GE, Xiao-ying WANG, and Yuan-lin SONG analyzed data and helped with the reagents. David GARFIELD and Ping YANG helped revise the paper. Chun-xue BAI designed and supervised the research.

\section{References}

1 Elzagallaai AA, Garcia-Bournissen F, Finkelstein Y, Bend JR, Rieder MJ, Koren G. Severe bullous hypersensitivity reactions after exposure to carbamazepine in a HAN-Chinese child with a positive HLA-B*1502 and negative in vitro toxicity assays: evidence for different pathophysiological mechanisms. J Popul Ther Clin Pharmacol 2011; 18 : e1-9.

2 Raychaudhuri P. FoxM1: a master regulator of tumor metastasis. Cancer Res 2011; 71: 4329-33.

3 Sun H, Teng M, Liu J, Jin D, Wu J, Yan D, et al. FOXM1 expression predicts the prognosis in hepatocellular carcinoma patients after orthotopic liver transplantation combined with the Milan criteria. Cancer Lett 2011; 306: 214-22.

4 Yu J, Deshmukh H, Payton JE, Dunham C, Scheithauer BW, Tihan $\mathrm{T}$, et al. Array-based comparative genomic hybridization identifies CDK4 and FOXM1 alterations as independent predictors of survival in malignant peripheral nerve sheath tumor. Clin Cancer Res 2011; 17 : 1924-34.

5 Balli D, Zhang Y, Snyder J, Kalinichenko VV, Kalin TV. Endothelial cellspecific deletion of transcription factor FoxM1 increases urethaneinduced lung carcinogenesis. Cancer Res 2011; 71: 40-50.

6 Wang X, Kiyokawa H, Dennewitz MB, Costa RH. The forkhead box m1b transcription factor is essential for hepatocyte DNA replication and mitosis during mouse liver regeneration. Proc Natl Acad Sci U S A 2002; 99: 16881-6.

7 Wang IC, Chen YJ, Hughes D, Petrovic V, Major ML, Park HJ, et al. 
Forkhead box M1 regulates the transcriptional network of genes essential for mitotic progression and genes encoding the SCF (SKP2-1) ubiquitin ligase. Mol Cell Biol 2005; 25: 10875-94.

8 aoukili J, Kooistra MR, Brás A, Kauw J, Kerkhoven RM, Morrison A, et al. FoxM1 is required for execution of the mitotic rogramme and chromosome stability. Nat Cell Biol 2005; 7: 126-36.

9 Wonsey DR, Follettie MT. Loss of the forkhead transcription factor FoxM1 causes centrosome amplification and mitotic catastrophe. Cancer Res 2005; 65: 5181-9.

10 lin TV, Wang IC, Ackerson TJ, Major ML, Detrisac CJ, Kalinichenko VV, et al. Increased levels of the FoxM1 transcription factor accelerate development and progression of prostate carcinamas in both TRAMP and LADY transgenic mice. Cancer Res 2006; 66: 1712-20.

11 Kim IM, Ackerson T, Ramakrishna S, Tretiakova M, Wang IC, Kalin TV, et al. The Forkhead Box m1 transcription factor stimulates the proliferation of tumor cells during development of lung cancer. Cancer Res 2006; 66: 2153-61.

12 Le XF, Pruefer F, Bast RC Jr. HER2-targeting antibodies modulate the cyclin-dependent kinase inhibitor p27Kip1 via multiple signaling pathways. Cell Cycle 2005; 4: 87-95.

13 Wakeling AE. Epidermal growth factor receptor tyrosine kinase inhibitors. Curr Opin Pharmacol 2002; 2: 382-7.

$14 \mathrm{~F}$ Ciardiello. Epidermal growth factor receptor inhibitors in cancer treatment. Future Onclo 2005; 1: 221-34.

15 Nelson MH, Dolder CR. Lapatinib: a novel dual tyrosine kinase inhibitor with activity in solid tumors. Ann Pharmacother 2006; 40: 261-9.

16 Wakeling AE, Guy SP, Woodburn JR, Ashton SE, Curry BJ, Barker AJ, et al. ZD1839 (Iressa): an orally active inhibitor of epidermal growth factor signaling with potential for cancer therapy. Cancer Res 2002; 62: 5749-54.

17 Hay N. The Akt-mTOR tango and its relevance to cancer. Cancer Cell 2005; 8: 179-83.

18 Morgillo F, Lee HY. Resistance to epidermal growth factor receptortargeted therapy. Drug Resist Update 2005; 8: 298-310.

19 Jia D, Yan M, Wang X, Hao X, Liang L, Liu L, et al. Development of a highly metastatic model that reveals a crucial role of fibronectin in lung cancer cell migration and invasion. BMC Cancer 2010; 10: 364-75.

20 Macha MA, Matta A, Chauhan S, Siu KM, Ralhan R. 14-3-3 zeta is a molecular target in guggulsterone induced apoptosis in head and neck cancer cells. BMC Cancer 2010; 10: 655-66.

21 Zheng Y, Ritzenthaler JD, Roman J, Han S. Nicotine stimulates human lung cancer cell growth by inducing fibronectin expression. Am J Respir Cell Mol Biol 2007; 37: 681-90.

22 Uchida A, Hirano S, Kitao H, Ogino A, Rai K, Toyooka S, et al. Activa- tion of downstream epidermal growth factor receptor (EGFR) signaling provides efitinibresistance in cells carrying EGFR mutation. Cancer Sci 2007; 98: 357-63.

23 Laoukili J, Stahl M, Medema RH. FoxM1: at the crossroads of ageing and cancer. Biochim Biophys Acta 2007; 1775: 92-102.

24 Myatt SS, Lam EW. The emerging roles of forkhead box (Fox) proteins in cancer. Nat Rev Cancer 2007; 7: 847-59.

25 Kwok JM, Peck B, Monteiro L, Schwenen HD, Millour J, Coombes RC, et al. FOXM1 confers acquired cisplatin resistance in breast cancer cells. Mol Cancer Res 2010; 8: 24-34.

26 Carr JR, Park HJ, Wang Z, Kiefer MM, Raychaudhuri P. FoxM1 mediates resistance to Herceptin and Paclitaxel. Cancer Res 2010; 70: 5054-63.

27 McGovern UB, Francis RE, Peck B, Guest SK, Wang J, Myatt SS, et al. Gefitinib (Iressa) represses FOXM1 expression via FOXO3a in breast cancer. Mol Cancer Ther 2009; 8: 582-91.

28 Estève PO, Chin HG, Pradhan S. Molecular mechanisms of transactivation and doxorubicin-mediated repression of survivin gene in cancer cells. J Biol Chem 2007; 282: 2615-25.

29 Androic I, Krämer A, Yan R, Rödel F, Gätje R, Kaufmann M, et al. Targeting cyclin B1 inhibits proliferation and sensitizes breast cancer cells to taxol. BMC Cancer 2008; 8: 391.

30 Rödel F, Hoffmann J, Distel L, Herrmann M, Noisternig T, Papadopoulos $\mathrm{T}$, et al. Survivin as a radioresistance factor, and prognostic and therapeutic target for radiotherapy in rectal cancer. Cancer Res 2005; 65: 4881-7.

31 Kato J, Kuwabara Y, Mitani M, Shinoda N, Sato A, Toyama T, et al. Expression of survivin in esophageal cancer: correlation with the prognosis and response to chemotherapy. Int J Cancer 2001; 95: 92-5.

32 Zaffaroni N, Pennati M, Colella G, Perego P, Supino R, Gatti L, et al. Expression of the anti-apoptotic gene survivin correlates with taxol resistance in human ovarian cancer. Cell Mol Life Sci 2002; 59 : 1406-12.

33 Suzuki T, Urano T, Miki Y, Moriya T, Akahira J, Ishida T, et al. Nuclear cyclin B1 in human breast carcinoma as a potent prognostic factor. Cancer Sci 2007; 98: 644-51.

34 Hassan KA, Ang KK, El-Naggar AK, Story MD, Lee Jl, Liu D, et al. Cyclin B1 overexpression and resistance to radiotherapy in head and neck squamous cell carcinama. Cancer Res 2002; 62: 6414-17.

35 Thatcher N, Chang A, Parikh P, Rodrigues Pereira J, Ciuleanu T, von Pawel J, et al. Gefitinib plus best supportive care in previously treated patients with refractory advanced non-small-cell lung cancer: results from a randomised, placebo-controlled, multicentre study (Iressa Survival Evaluation in Lung Cancer). Lancet 2005; 366: 1527-37. 